\title{
ARISTOTLE AND THE ANCIENT PUZZLE ABOUT COMING TO BE
}

\author{
TIMOTHY CLARKE
}

\section{Introduction}

Aristotle's project in the first book of the Physics is to develop a theory of the principles of natural beings. According to this theory, as set out in Physics I. 7, the generation of a natural substance is a process whereby an underlying substratum (the matter) goes from having a certain privation to having the relevant form. The resulting substance is a composite of the substratum and the form. These three items- the substratum, the form, and the privation-are the principles of natural beings.

Aristotle holds that a major benefit of this theory of principles is that it allows him to solve a long-standing puzzle about the possibility of coming to be. But how it is supposed to do this is not immediately obvious, in large part because it is not obvious how he understands the puzzle. The puzzle is described at the beginning of Physics I. 8:

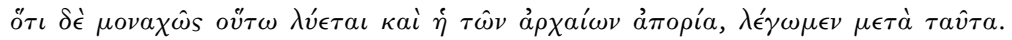

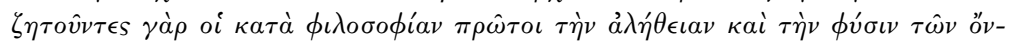

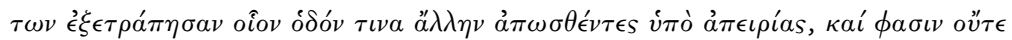

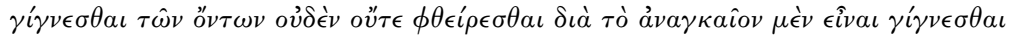

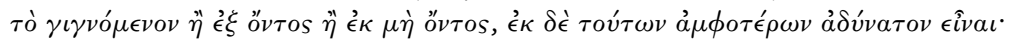

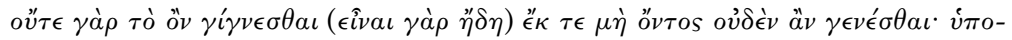

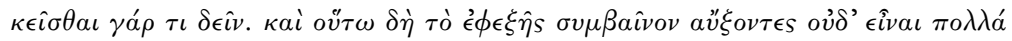

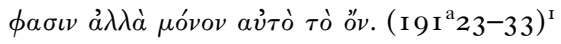

\section{(C) Timothy Clarke 2015}

I am grateful to Verity Harte, Alan Code, Andreas Anagnostopoulos, Klaus Corcilius, Scott O'Connor, Derin McLeod, Harvey Lederman, Hendrik Lorenz, and Brad Inwood for their helpful comments on earlier drafts of this paper. I have also benefited from the feedback of the participants in my Fall 2013 seminar at Berkeley, and from discussions with audiences at Berkeley, Birkbeck, Georgetown, Iowa, King's College London, the University of Massachusetts at Amherst, Munich, New York University, San Francisco State, Stanford, Washington University in Saint Louis, and Yale.

${ }^{1}$ I follow the Greek text of W. D. Ross, Aristotle's Physics: A Revised Text with Introduction and Commentary [Physics] (Oxford, I936), except where noted. 
And let us next say that, in addition, it is only in this way ${ }^{2}$ that the puzzle of the ancients is resolved. For the first people to proceed philosophically got turned off course in their enquiry after truth and the nature of things, driven as it were onto some other road by their inexperience, and they say that none of the things that are either comes to be or passes away. This is because what comes to be must come to be either from what is or from what is not, ${ }^{3}$ and yet it is impossible [for a thing to come to be] from either of these. For what is does not come to be, since it already is; and nothing could have come to be from what is not, since something must underlie. And what is more, exaggerating what next follows from this, they deny that the many are, and say that only what is itself is.

In this paper I want to do two things. First, I want to explain the puzzle about coming to be as it is described here. The interpretation I shall defend is a relatively straightforward one, although it has generally been overlooked in the literature on the passage. Second, I want to explain how Aristotle's theory of principles resolves the puzzle, as I suggest we interpret it.

My plan is as follows. I shall start, in Section 2, by addressing two preliminary questions: (a) about the identity of the 'ancients' to whom Aristotle ascribes the puzzle; and $(b)$ whether the puzzle concerns coming into existence or coming to be such-and-such. I shall then, in Section 3, turn to the question of how to understand the puzzle's two options about coming to be ('what comes to be must come to be either from what is or from what is not'). This is where I give my interpretation of the puzzle and explain its advantages over other interpretations. After that, in Section 4, I shall examine Aristotle's discussion of how the puzzle is to be resolved.

\section{Two preliminary questions}

We can begin with the question of who the 'ancients' are. Like most other interpreters, I take Aristotle to be thinking primarily of the Eleatics, specifically Parmenides and Melissus. But he does not name names, ${ }^{4}$ and his description of these people as 'the first to pro-

\footnotetext{
${ }^{2}$ The reference is to the theory of principles given in the previous chapter. It is only with this theory that we are able to solve the puzzle.

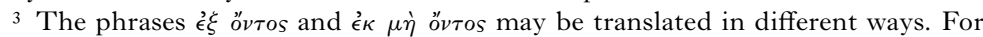
now I use the translations 'from what is' and 'from what is not'; later in the paper I shall also use the alternative translations 'from being' and 'from non-being'.

${ }^{4} \mathrm{He}$ does mention Parmenides by name at the beginning of $\mathrm{I} .9\left(192^{\mathrm{a}} \mathrm{I}\right)$, but this
} 


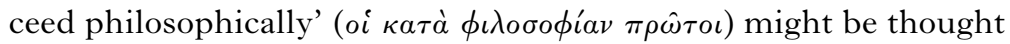
to suggest that he is talking about early Greek philosophers in general, rather than about the Eleatics in particular. ${ }^{5}$

Nevertheless, it seems likely that he has the Eleatics uppermost in mind. We can detect a sly allusion to Parmenides' roads of enquiry

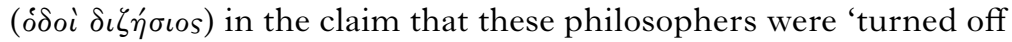
course in their enquiry ... driven as it were onto some other road

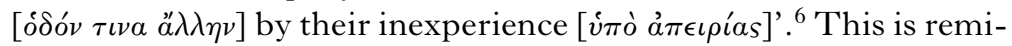
niscent of Parmenides B 7. 3, where the goddess warns the kouros not to let 'habit born of much experience [ $\left.{ }^{\prime} \theta 0 s \pi o \lambda \dot{v} \pi \epsilon \iota \rho o \nu\right]$ ' force him down the wrong road. ${ }^{7}$

Further evidence that Aristotle is thinking of the Eleatics is that he says these philosophers were also led, as a result of their denial of coming to be and passing away, to deny that 'many things are', and to say that 'only what is itself is' ( $\mathrm{I}_{9 \mathrm{I}}{ }^{\mathrm{a}} 3 \mathrm{I}-3$; cf. $\left.\mathrm{I} 9 \mathrm{I}^{\mathrm{b}} \mathrm{I} \mathrm{I}-\mathrm{I} 3\right)$. This sounds very much like Eleatic monism, and closely matches Aristotle's description of Eleatic monism in other passages. ${ }^{8}$

My second preliminary question is how we should understand the ancients' conclusion: that coming to be is impossible. The verb $\gamma^{\prime}$ ' $\nu \in \sigma \theta a \iota$ ('to come to be') can denote coming into existence, but it also has an incomplete use: 'to come to be $F$ '. So the argument Aristotle presents might be denying the possibility of coming into existence, or it might be denying the possibility of coming to be $F$ (for any value of $F$ ). ${ }^{9}$

I take the puzzle to be first and foremost a puzzle about coming into existence. Immediately before he articulates the puzzle, Aris-

need not imply that he takes the puzzle described in the previous chapter to be a specifically Eleatic puzzle.

5 This is the view of J. Palmer, Parmenides and Presocratic Philosophy (Oxford, 2009), 130-3.

${ }^{6}$ Cf. also F. M. Cornford, Plato and Parmenides (London, I939), 38 n. 2; A. Madigan, 'Commentary on Loux', Proceedings of the Boston Area Colloquium in Ancient Philosophy, 8 (I 992), 320-7 at 323.

7 Note that the allusion to Parmenides' roads of enquiry is there even if the correct

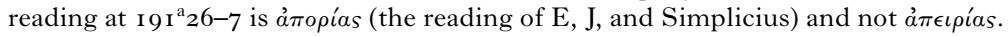

${ }^{8}$ Compare the description of Parmenides' position at Phys. I. 3, I $87^{\mathrm{a}} 7$ (there is nothing else 'beside what is itself') and also at Metaph. A 5, 986 ${ }^{\mathrm{b}} 29-30$ ('what is is one, and nothing else is').

9 For the former interpretation see e.g. P. H. Wicksteed and F. M. Cornford, Aristotle: The Physics, Books I-IV (Cambridge, Mass., I 934), 85; Ross, Physics, 346; W. Charlton, Aristotle: Physics, Books I and II [Physics I-II] (Oxford, I 970), 80. For the latter interpretation see A. Code, 'Aristotle's Response to Quine's Objections to Modal Logic' ['Response'], Fournal of Philosophical Logic, 5 ( I 976), I 59-86 at I 63. 
totle says that these philosophers 'say that none of the things that are either comes to be or passes away' $\left(\mathrm{I}_{9} \mathrm{I}^{\mathrm{a}} 27\right)$. The puzzle that follows ('for what comes to be must come to be either from what is or from what is not') explains the reasoning behind this denial of coming to be and passing away. The verb 'comes to be' at $\mathrm{I}_{9 \mathrm{I}} \mathrm{I}^{\mathrm{a}} 27$ is most naturally taken in the sense of 'comes into existence', paired as it is with the verb 'passes away' $(\phi \theta \epsilon i \rho \epsilon \sigma \theta \alpha \iota) .{ }^{10}$ So the uses of 'comes to be' in the following lines, in the description of the puzzle, are most naturally taken in the same way. And so it would seem that Aristotle is describing a puzzle about coming into existence.

Note that this reading is quite consistent with the fact that Aristotle takes the puzzle to have led to the rejection of 'change in general' ( $\left.\mathrm{I}_{9} \mathrm{I}^{\mathrm{b}} 33\right)$. This is because the possibility of other kinds of change can seem to depend on the possibility of coming into and going out of existence. Indeed, the Eleatics argued against other kinds of change on exactly this basis. Parmenides' argument against motion ( iv $\eta \sigma \iota)$ appeals to his earlier rejection of coming into and going out of existence (B 8. 26-8). And Melissus reasons from the impossibility of coming into and going out of existence to the impossibility of alteration and rearrangement (B 7. 2-3 and 8. 6).

\section{The puzzle}

We can now turn to the details of the argument against coming to be. In Aristotle's presentation, the first premiss of the argument is that 'what comes to be must come to be either from what is or from what is not' $\left(\mathrm{I}^{9} \mathrm{I}^{\mathrm{a}} 28-9\right)$. Both options are argued to be impossible $\left({ }^{\mathrm{a}} 29-3 \mathrm{I}\right)$, and from this it is inferred that nothing can come to be.

It is standard to distinguish two types of reading of the first premiss. Like the verb $\gamma^{\prime}(\gamma \nu \in \sigma \theta a \iota$, the verb eival ('to be') has a complete and an incomplete use. Correspondingly, there appear to be two different ways in which one might take the distinction between coming to be 'from what is' and 'from what is not'. On the first type of reading (the 'existential' reading), 'is' has its complete use and

Io For a thing to pass away is for it to cease to exist. Aristotle sometimes uses 'passing away' in connection with cases of non-substantial change; for example, the process whereby a thing ceases to be musical can be described as 'the passing away of the musical into the non-musical' (see Phys. I. 5, I $88^{\mathrm{b}} 3^{-8}$ ). But even here something's 'passing away' is a matter of its ceasing to exist. I take it that $X$ passes away 'into $Y$ ' when $X$ goes out of existence and is replaced by $Y$. 
means 'exists': what comes into existence must do so either from what exists or from what does not exist. ${ }^{\text {II }}$ On the second type of reading (the 'incomplete' reading), the phrases 'from what is' and 'from what is not' are elliptical and require a complement. Ross, who endorses the second type of reading, suggests that the claim is that anything that comes into existence must do so either from what is $i t$ or from what is not it. ${ }^{\mathrm{I} 2}$

Both types of reading have been thought to face difficulties. The difficulties emerge when one considers the arguments given against each option:

... it is impossible [for a thing to come to be] from either of these [sc. either from what is or from what is not]. For (I) what is does not come to be, since it already is; and (2) nothing could have come to be from what is not, since something must underlie. ( I $^{\mathrm{a}}{ }^{\mathrm{a}} 29-3 \mathrm{I}$ )

Clearly we want a reading of the two options- 'from what is' and 'from what is not' - that makes sense of both of these subarguments. But the existential reading seems unable to make sense of the first subargument. Sean Kelsey puts the problem as follows:

The trouble [with the existential reading] is that the proposal that things come to be from 'what is' appears untouched by the objection raised against it, namely that 'it is already.' Why should it follow, just because Socrates comes to be from something that 'is' (period), that he already was, before he came to be? Surely he might have come from some other thing that 'is,' for example from an egg or a seed. ${ }^{13}$

It is true that what already is (what already exists) cannot now come into existence. As Kelsey explains, the problem is that this seems irrelevant to the matter at hand. What we want to know is why a new thing cannot come into existence from what already exists. To change the example, suppose that a house comes into existence

${ }^{1}$ For this type of reading, see M. J. Loux, 'Aristotle and Parmenides: An Interpretation of Physics A 8', Proceedings of the Boston Area Colloquium in Ancient Philosophy, 8 (1 992), 28I-3 I 9 at 282-7; T. M. Horstschäfer, 'Über Prinzipien': Eine Untersuchung zur methodischen und inhaltlichen Geschlossenheit des ersten Buches der Physik des Aristoteles (Berlin, I 998), 384-99.

${ }^{\mathrm{I} 2}$ Ross, Physics, 494. Other defenders of this type of reading include Code, 'Response', I 63-4, and S. Waterlow, Nature, Change, and Agency in Aristotle's Physics: A Philosophical Study (Oxford, I 982), 8-го. The most detailed exposition and defence of an incomplete reading is A. Anagnostopoulos, 'Aristotle's Parmenidean Dilemma' ['Dilemma'], Archiv für Geschichte der Philosophie, 95 (2013), 245-74.

I3 S. Kelsey, 'Aristotle Physics I 8' ['I 8'], Phronesis, 5I (2006), 330-6I at 333-4. See also Ross, Physics, 494; Code, 'Response', I63. 
from something that already exists-a pile of bricks, say. ${ }^{14}$ Once the bricks exist, it is obviously true that they cannot come into existence. But what we want to know is why the house cannot come into existence. The house and the bricks are non-identical (the house does not yet exist, the bricks do). So the fact that the bricks already exist does not mean that the house cannot come into existence.

The incomplete reading, by contrast, seems to have a hard time making sense of the second subargument. As Kelsey puts the difficulty, 'Why should it follow, just because Socrates comes to be from something that is not Socrates, that he comes to be from nothing at all (or from nothing that "underlies")?' 5 Again, to switch the example, think of the house and the bricks from which it comes to be. In this case, the house comes into existence from what is not $i t$ : the house and the bricks are non-identical. The difficulty is: why should it follow from this that nothing underlies the process of coming into existence? It seems that we have just identified something that underlies the process, namely, the bricks. ${ }^{16}$

Motivated by the difficulties facing the existential and incomplete readings, Kelsey suggests an alternative reading of the distinction between coming to be from what is and from what is not. On this view, the distinction should be interpreted as a distinction between coming to be from what is a substance and coming to be from what is not a substance. ${ }^{17}$

Kelsey suggests that the first option (a thing comes to be from what is a substance) is ruled out on the grounds that it violates an apparently plausible principle about generation: 'nothing can come to be the kind of thing it already is'. Kelsey takes the argument to assume that whenever one entity comes to be another, what the original entity comes to be is a substance (among other things). Thus, a new substance cannot come to be from a precursor which is also

${ }^{14}$ I shall follow Aristotle himself in using artefacts as illustrative examples, with the caveat that the real concern of Physics $\mathrm{I}$ is the generation of natural beings.

15 Kelsey, 'I 8', 334. Cf. also Loux, 'Aristotle and Parmenides', 289.

${ }^{16}$ On Anagnostopoulos's version of the incomplete reading, the second option about coming to be is that what is $F$ comes to be from what is not $F$. This is ruled out, Anagnostopoulos suggests, on the grounds that 'what is not $F$ ' is not itself what underlies the process of becoming $F$ ('Dilemma', 262-3). But as I read the argument against the second option ('since something must underlie'), the implication is that-on this option-nothing underlies. Accordingly, I think that a defender of the incomplete reading must explain why, if what is $F$ comes to be from what is not $F$, it seems to follow that nothing underlies this process (and not merely: that what is not $F$ does not itself underlie this process).

${ }^{17}$ Kelsey, 'I 8', 335-8. 
a substance, without this violating the principle that 'nothing can come to be the kind of thing it already is'. This is why a thing cannot come to be from something that is a substance.

The second option (a thing comes to be from what is not a substance) is ruled out on the grounds that non-substances cannot 'underlie'. Here we might think of Cat. $5,4^{\mathrm{a}}{ }^{\mathrm{I}} \mathrm{O}^{\mathrm{b}}{ }^{\mathrm{I}} \mathrm{9}$, where nonsubstances are taken to be incapable of undergoing, or being the subjects of, changes. Since anything that comes to be must do so either from what is a substance or from what is not a substance, it therefore follows that nothing can come to be.

Kelsey stresses that an important merit of this reading is that it makes the puzzle depend on principles that Aristotle himself accepts (at least in some form or other). This allows us to explain why he takes the puzzle seriously. ${ }^{18}$ Nevertheless, the reading also has its drawbacks. One problem is that, as we have seen, Aristotle regards the puzzle as an Eleatic puzzle. Yet on Kelsey's interpretation the puzzle presupposes a sophisticated Aristotelian distinction between substances and non-substances, and it may be doubted whether Aristotle would want to credit his Eleatic predecessors with such a distinction. A second problem is that Aristotle gives us no indication that he is using 'is' and 'is not' to mean 'is a substance' and 'is not a substance'. If he had wanted to distinguish between coming to be from what is and from what is not a substance, he could easily have done so explicitly. The fact that he does not do so suggests that it would be preferable for us to find-if we can-an interpretation that takes the distinction between 'is' and 'is not' at face value.

I think, therefore, that we should reconsider the prospects for an existential reading of the two options. On the existential reading, recall, the claim is that what comes into existence must do so either from what exists or from what does not exist. Now, this is standardly taken as giving us two options about the precursor of the generated thing. (The 'precursor' of the generated thing is whatever it is that becomes the generated thing, as the seed becomes the plant, or the bricks become the house.) Either the precursor is something that exists, or it is something that does not exist. On this version of the existential reading we run into the problem raised earlier: it is difficult to make sense of the argument against the first option ('what is does not come to be, since it already is'). The fact that the 
precursor already exists is irrelevant to the matter at hand, given that the precursor and the generated thing are non-identical.

There is, however, another possibility. We could also take the two options as options not about the precursor of the generated thing, but about the generated thing itself. More precisely, we could take them to be options about the pre-generation state of the thing that comes to be. Did the generated thing come to be from what is-that is to say, from its previously being in a state of existence? Or did it come to be from what is not-that is to say, from its previously being non-existent? ${ }^{\text {19 }}$

My proposal is that once we understand the two options in this way, we avoid the above problem for the existential reading. In other words, if we understand the two options as being about the pre-generation state of the generated thing, it is possible to make sense of both of the subarguments. ${ }^{20}$

Start with the argument against the first option. On the interpretation I am suggesting, the first option is that the generated thing comes into existence from its previously being existent. This is clearly impossible, and it is impossible for exactly the reason Aristotle gives in the text: something that exists cannot now come into existence, for it already exists. The generated thing's existence is naturally thought of as the end state of the process of generation. Something that is already in this state cannot now come into it, just as something that is already pale cannot now come to be pale.

The second option, on the present interpretation, is that the generated thing comes into existence from its previously being nonexistent. This is meant to be impossible because 'something must underlie'. Once again, our interpretation allows us to understand this. It is tempting to conceive of coming to be as a change or a process undergone by the thing that comes to be. This is encouraged by the way we speak: one might easily suppose that, just as the

I9 On this interpretation, the function of 'from' ( $(\hat{\epsilon} \kappa)$ in Aristotle's formulation of the puzzle is the same as in the sentence 'The person changes to dark from pale [' $\epsilon \kappa$

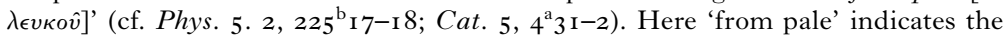
pre-change state of the thing that comes to be dark: the person comes to be dark from their previously being pale.

${ }^{20}$ Early in his paper, Loux gives a paraphrase of the puzzle which takes the two options in the way I am suggesting, as concerning the pre-generation state of the generated thing: 'given any object, $x$, if $x$ has come to be, then either $x$ preexisted its coming to be or it did not . .' ('Aristotle and Parmenides', 282). However, this is not Loux's considered view. On the interpretation that he goes on to offer $(282-7)$, the two options concern the generated thing's precursor. 
subject of the process coming to be pale is the thing that comes to be pale, and the subject of the process coming to be knowledgeable is the thing that comes to be knowledgeable, so too the subject of the process coming to be is the thing that comes to be. Yet on this conception of coming to be it seems impossible for a thing to come to be from its previously being non-existent. For how could something that is initially non-existent undergo a process or a change? After all, something non-existent cannot be affected in any way, and given that it cannot be affected, there would seem to be nothing that could ever cause it to go from one state (non-existence) to another (existence) ${ }^{21}$ In short, if a thing comes to be from being non-existent, generation would seem to be a change whose subject (at least at the outset) does not exist, which is impossible: in any change, 'something must underlie'.

We can therefore see how the present interpretation makes good sense of the puzzle described at $19 \mathrm{I}^{\mathrm{a}} \mathbf{2} 3-3 \mathrm{I}$. There is reason to think that if a new thing comes into existence, it cannot do so from its being existent, since its existence would seem to be the end state of the process. It is also tempting to think that the new thing cannot come into existence from its being non-existent, since it is hard to see how something non-existent could undergo (be the subject of, underlie) a change. Moreover, it is easy to see why these two options should seem to be exhaustive. Prior to coming into existence, the generated thing either existed or did not exist. So it is natural to suppose that it came into existence either from its being existent or from its being non-existent. As neither option seems possible, it seems to follow that nothing can come into existence.

This interpretation has significant advantages over the alternatives. Unlike Kelsey's interpretation, it avoids making the puzzle presuppose an Aristotelian distinction between substances and non-substances, and it instead takes the passage's distinction between being and non-being at face value-as a distinction between (as we would put it) existence and non-existence. Further, as we have just seen, the present interpretation allows us to give satisfying explanations of both of the subarguments, making it

${ }^{21}$ Compare Parmenides B 8. 9-ıо: 'And what need would have stirred it | later

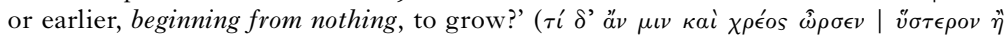
$\pi \rho \sigma^{\prime} \sigma \theta \epsilon \nu, \tau o \hat{v} \mu \eta \delta \epsilon \nu \grave{s} \dot{\alpha} \rho \xi \dot{\alpha} \mu \epsilon \nu o \nu, \phi \hat{v} v$;). If, prior to coming into existence, the thing did not exist-i.e. was nothing — what could ever have 'stirred' it into coming to be? (For this interpretation of Parmenides' argument, cf. J. Barnes, The Presocratic Philosophers, rev. edn. (London, I982), I88.) 
preferable to the first two readings we considered (the incomplete reading and the standard version of the existential reading).

\section{Resolving the puzzle}

Having considered Aristotle's account of the puzzle, I next want to examine his discussion of the puzzle's solution, which occupies the rest of chapter 8 . I take it that the main goal of the remaining part of the chapter is to justify the earlier claim that we can resolve the Eleatic puzzle by means of the theory of principles of chapter 7 ( $\left.19 \mathrm{I}^{\mathrm{a}} 23-4\right)$. Aristotle now mentions two ways ( $\left.\tau \rho \operatorname{co}_{\pi \circ} \iota\right)$ of addressing the puzzle. ${ }^{22}$ Most of his time is spent on the first way, which appeals to a distinction between coming to be from something nonaccidentally and coming to be from something accidentally ( $\mathrm{I}_{9 \mathrm{I}}{ }^{\mathrm{a}} 33^{-}$ ${ }^{b} 27$ ). He then briefly alludes to (but does not spell out) a second way of addressing the puzzle, which appeals to the distinction between actuality and potentiality $\left(\mathrm{I}_{9} \mathrm{I}^{\mathrm{b}} 27-9\right)$. Finally, in a short concluding section, he locates what he takes to be the ultimate source of the Eleatics' confusion about the possibility of coming to be ( $\left.\mathrm{I}_{9 \mathrm{I}}{ }^{\mathrm{b}} 3 \mathrm{O}-4\right)$.

\section{I. The first way of addressing the puzzle}

Aristotle's first way of addressing the puzzle distinguishes between coming to be from something non-accidentally and coming to be from something accidentally. This distinction is explained in the following lines:

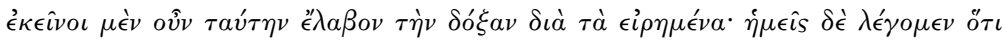

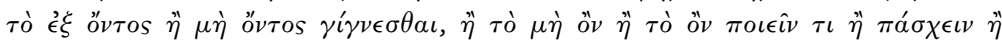

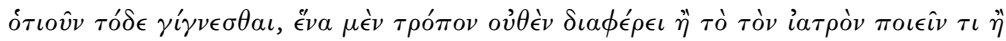

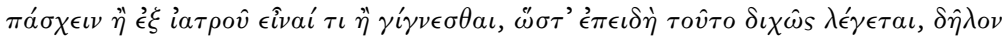

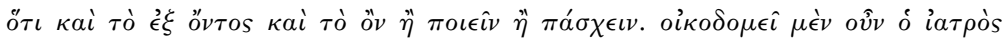
ởx $\hat{\eta}$ ia

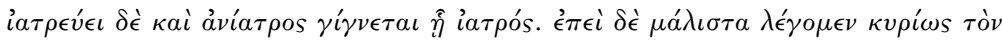

${ }^{22}$ This may initially strike us as odd, given his earlier claim that it is only in this

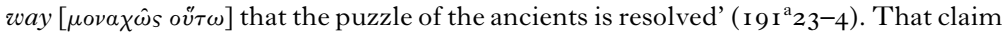
might seem to imply that there is only one way of addressing the puzzle. Yet the earlier claim is, in fact, consistent with what happens later in chapter 8. I suggest

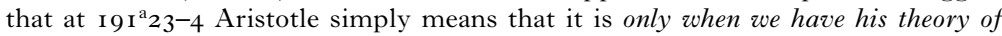
principles that we are able to resolve the puzzle. This is compatible with there being multiple ways of addressing the puzzle, as long as each of these makes use of Aristotle's theory of principles. 


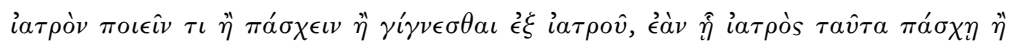

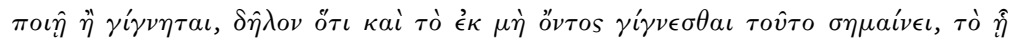
$\mu \grave{\eta}$ oै $\nu$. ( I9I ${ }^{\mathrm{a}} 33^{-\mathrm{b}} \mathrm{IO}$ )

So those philosophers held this opinion for the aforementioned reasons. We, on the other hand, say that to come to be from being or from non-being, ${ }^{23}$ or for what is not or what is to do something, or undergo something, or come to be any particular this-all this is in a way no different from the doctor doing or undergoing something, or from being or coming to be something from doctor. So, since these [sc. the phrases referring to the doctor] are said in two ways, it is clear that 'from being', 'what is does', and 'what is undergoes' are also [said in two ways]. On the one hand, the doctor builds a house not qua doctor but qua housebuilder, and he comes to be pale not qua doctor but qua dark. On the other hand, he heals and comes to be unmedical qua doctor. But since it is most proper to say that 'the doctor' does something or undergoes [something], or comes to be [something] 'from doctor', if he undergoes, does, or comes to be these things qua doctor, it is clear that 'coming to be from non-being' also signifies this: [coming to be from non-being] qua non-being.

Think of a doctor who also happens to be a skilled housebuilder, and who builds herself a house. It is true that the doctor builds a house. But it is not qua doctor that she builds a house. It is not by virtue of her being a doctor that she is able to perform the task in question, but by virtue of her being a housebuilder. Contrast this with the doctor's healing one of her patients. It is true that the doctor heals her patient. And in this case it is qua doctor that she performs the task in question. It is precisely by virtue of her being a doctor that she is able to heal her patient. We can put this distinction by saying that the doctor builds accidentally, whereas the doctor heals non-accidentally.

The same sort of distinction can be drawn with regard to coming to be something from something. Think of a doctor who, in the winter, loses her summer tan. It is true-according to Aristotlethat the doctor comes to be pale from (being a) doctor. But it is not qua doctor that she undergoes this process. It is not by virtue of her having been a doctor that she was able to become pale, but by virtue of her having been tanned. Contrast this with the doctor's becoming

${ }^{23}$ At this point in the text I find it preferable to translate the phrases $\epsilon^{\prime} \xi$ oै $\nu \tau o s$ and $\dot{\epsilon}^{\prime} \kappa \mu \grave{\eta}{ }^{\prime} \nu \tau o s$ as 'from being' and 'from non-being'. My reason is that Aristotle's posi-

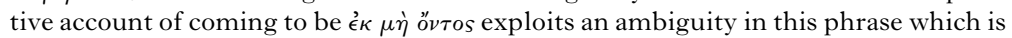
preserved by the translation 'from non-being', but lost in the translation 'from what is not'. See n. 28 below. 
'unmedical'. (Suppose she stops practising and eventually loses her expertise.) It is true that the doctor becomes unmedical from (being a) doctor. And in this case it is qua doctor that she undergoes the process. It is precisely by virtue of her having been a doctorthat is, by virtue of her having had medical expertise-that she was able to lose this expertise and become unmedical. We can put the distinction by saying that the doctor comes to be pale from (being a) doctor accidentally, whereas the doctor comes to be unmedical from (being a) doctor non-accidentally.

Generalizing now, we can state Aristotle's distinction as follows:

The $F \varphi$ s non-accidentally just in case:

(i) the $F \varphi s$; and

(ii) it is by virtue of its being $F$ that the $F$ is able to $\varphi$.

The $F$ s accidentally just in case:

(i) the $F \varphi s$; but

(ii) it is not by virtue of its being $F$ that the $F$ is able to $\varphi$.

$X$ comes to be $F$ from $G$ non-accidentally just in case:

(i) $X$ comes to be $F$ from $G$; and

(ii) it is by virtue of $X$ 's having been $G$ that $X$ was able to come to be $F$.

$X$ comes to be $F$ from $G$ accidentally just in case:

(i) $X$ comes to be $F$ from $G$; but

(ii) it is not by virtue of $X$ 's having been $G$ that $X$ was able to come to be $F$.

4.I.I. Coming to be from non-being With this distinction in place, Aristotle can use it to identify unproblematic ways in which, according to his theory of principles, a thing comes to be both from being and from non-being. He begins with coming to be from nonbeing:

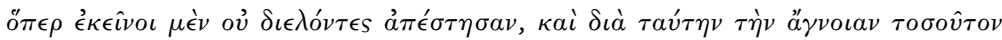

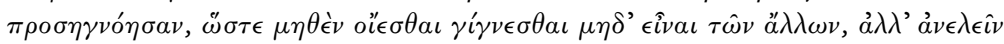

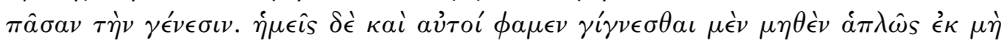

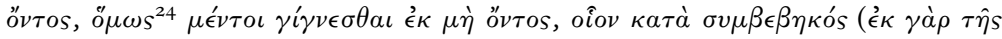

${ }^{24}$ Reading ö $\mu \omega s$ with manuscripts F, I, and J, rather than Cornford's emendation $\pi \dot{\omega}$ s. Cf. L. Angioni, Aristóteles: Física I-II (Campinas, 2009), I 77. 


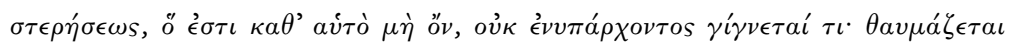

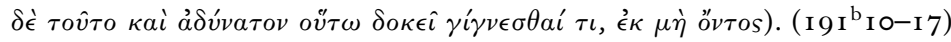

Failing to make this distinction, those people gave the matter up. And on account of this ignorance they went so far wrong, in addition, that they thought that none of the other things either comes to be or is, but instead they abolished coming to be as a whole. ${ }^{25}$ But we ourselves also say that nothing comes to be from non-being without qualification; yet [we say that] a thing nevertheless does come to be from non-being, that is to say, [it comes from non-being] accidentally. (For a thing comes to be from the privation, which is in itself non-being-this not being present [in the product $].{ }^{26}$ But this is thought amazing, and it seems impossible for something to come to be in this way, from non-being.)

Aristotle holds that there is a sense in which the Eleatics were right to deny that a thing comes to be from non-being: a thing does not come to be from non-being 'without qualification', that is to say, non-accidentally. But, crucially, this is not the only way of coming to be from non-being. On Aristotle's own view of generation, a thing comes to be from non-being accidentally, and this is unproblematic.

Why does Aristotle hold that a thing comes to be from non-being accidentally rather than non-accidentally? We can explain this by drawing on our above account of the accidentally/non-accidentally distinction. If that account is correct, $X$ comes to be from nonbeing accidentally (rather than non-accidentally) just in case:

(i) $X$ comes to be from non-being; but

(ii) it is not by virtue of $X$ 's having been a non-being that $X$ was able to come to be.

Begin with (ii). Why, exactly, would it be wrong to say that a statue (say) was able to come to be by virtue of its having been a non-being? Aristotle does not tell us, but his thought may be the

${ }_{25}$ Here Aristotle refers to the supposed further consequences of the Eleatic rejection of generation: first, monism ('none of the other things [sc. besides what is itself] either comes to be or is'); second, the rejection of change in general ('they abolished coming to be as a whole').

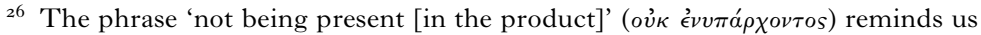
that although a thing comes to be from the privation, the privation does not survive the change. Contrast the substratum: a thing also comes to be from the substratum, and this remains as a component of the final product. Cf. the description of the material cause at Phys. 2. 3, I $94^{\mathrm{b}} 23-4$ : 'that from which a thing comes to be and which

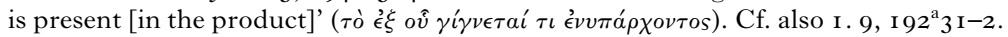


following. Many non-beings are necessary non-beings: non-beings that cannot possibly come to be. (For Aristotle examples would include a second cosmos or an infinitely extended body.) So the mere fact that the statue was previously a non-being fails to explain why it was able to come to be. Rather, what explains this is the fact that the statue-or, more accurately, the thing that now has the form of the statue-was previously an unshaped block of marble: an entity capable of possessing the statue form, but actually lacking it.

Now to (i). According to Aristotle's theory of principles we can say that the generated thing comes to be from the relevant privation, inter alia. ${ }^{27}$ We can say that the statue, for instance, comes to be from the privation of the form of the statue. Aristotle tells us that the privation 'is in itself non-being [ $\mu$ ' $\left.^{\circ} \nu\right]$ ' (cf. also I. 9, I 92 ${ }^{\mathrm{a}} 3-6$ ). I suggest that by this he means that a privation is a particular kind of non-being: the absence or non-existence of a particular form, in the sort of thing that is capable of receiving that form. (This is just what a privation is; hence a privation is essentially or 'in itself' a kind of non-being. ${ }^{28}$ ) Thus, if it is true that the statue comes to be from the relevant privation, it is also true that the statue comes to be 'from non-being'. ${ }^{29}$

If a thing comes to be 'from non-being' in this way, we do not encounter the problem raised in the puzzle ('nothing could have come to be from non-being, since something must underlie', $19 \mathrm{I}^{\mathrm{a}} 3 \mathrm{O}-\mathrm{I}$ ). When the statue comes to be from the relevant privation, what happens is that an existing thing, the marble, changes from having the

27 A thing is also said to come to be from the substratum and from the form: 1.7 , I $90^{\mathrm{b}} \mathrm{I}$ 7-20. I should point out that, unlike some interpreters (e.g. Loux, 'Aristotle

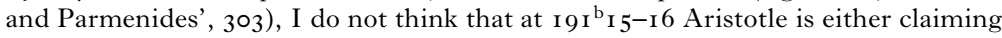
or assuming that a thing comes to be from the relevant privation only accidentally. This would be hard to square with I. $5,188^{\mathrm{a}} 3 \mathrm{O}^{-} \mathrm{b}_{23}$, which strongly suggests that he thinks that a thing comes to be from the relevant privation non-accidentally.

${ }^{28}$ In saying that something is (a) 'non-being' ( $\mu$ ' ${ }^{\circ} \nu$ ), Aristotle sometimes means that it is an instance of what is not, or what is non-existent. Prior to coming to be, the statue was a non-being in this sense. However, this does not seem to be what he means when he says that the privation is in itself 'non-being'. After all, privations exist. So my suggestion is that the privation is 'non-being' in the sense of being the absence or non-existence of a particular form. This is why I use the expression 'nonbeing'-rather than 'what is not'-to translate $\mu \eta \dot{~} o^{\prime} \nu$ in this part of the chapter. The privation is essentially (a kind of) non-being, but it is not essentially an instance of what is not.

${ }^{29}$ Compare: Green is a species of colour. So, if it is true that the apple comes to be red from green, it is also true that the apple comes to be red from (a) colour. 
privation (a kind of non-being) to having the form. Since the marble is the subject of this process, and exists throughout, we avoid the Eleatic worry that nothing underlies. ${ }^{3 \circ}$

4.r.2. Coming to be from being In the next section Aristotle adds that there is likewise an unproblematic way in which, according to his theory of principles, a thing can be said to come to be from being:

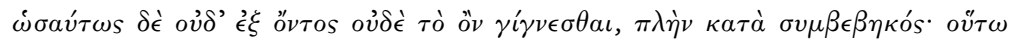

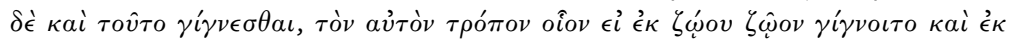

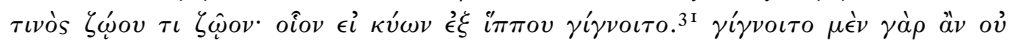

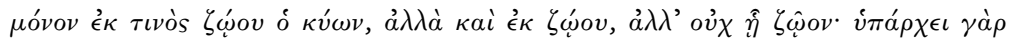

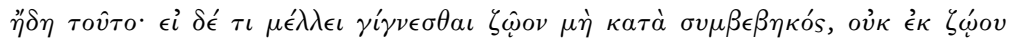

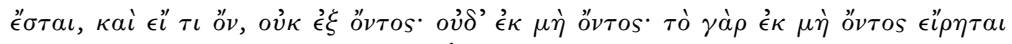

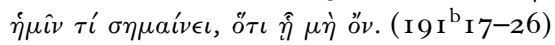

And in the same way, we say that neither does a thing come to be from being, nor does what is come to be, except accidentally. But in this way [sc. accidentally] we say that this [sc. what is] too comes to be; in the same way, for instance, as if an animal should come be from an animal, that is, a particular animal from a particular animal. For example, if a dog should come to be from a horse. For the dog would then come to be not only from a particular animal [sc. a horse], but also from an animal, although it would not come to be qua animal. For this [sc. animal] already belongs [sc. to the horse]. But if something is going to come to be an animal non-accidentally, it will not do so from an animal. And if something is going to come to be a being [non-accidentally], it will not do so from being. Nor indeed will it do so from non-being. For we have said what 'from non-being' signifies, namely, 'qua non-being'.

This section makes two main points, each of which is stated in the opening sentence:

$3^{\circ}$ I have not said anything here about the second sentence of the parenthesis: 'But this is thought amazing, and it seems impossible for something to come to be in this way, from non-being' $\left(19 \mathrm{I}^{\mathrm{b}} \mathrm{I} 6-17\right)$. I take the point of this sentence to be that although there is an unproblematic way in which a thing comes to be from nonbeing, this (i.e. coming to be from non-being) is nevertheless thought to be impossible.

${ }^{31}$ Following the manuscript reading rather than the supplement proposed by E. Laas (Aristotelische Textes-Studien (Berlin, I 863), 28) and adopted by Ross: $\epsilon \hat{\imath} \kappa v ́ \omega \nu$

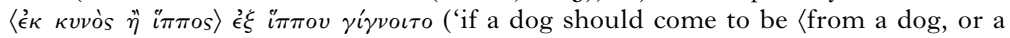
horse $\rangle$ from a horse'). It is now generally accepted that this supplement is mistaken. See e.g. H. Wagner, Aristoteles: Physikvorlesung (Berlin, I 967), 440; Loux, 'Aristotle and Parmenides', 3 I I ; Kelsey, 'I 8', 35 I n. 35; Anagnostopoulos, 'Dilemma', 269. 
(A) A thing does not come to be from being, except accidentally.

(B) What is does not come to be, except accidentally.

We can explain claim (A) by once again drawing on our earlier account of the accidentally/non-accidentally distinction. According to that account, a thing $X$ comes to be from being accidentally (rather than non-accidentally) just in case:

(i) $X$ comes to be from being; but

(ii) it is not by virtue of $X$ 's having been a being that $X$ was able to come to be.

On Aristotle's theory it is true that the statue comes to be 'from being' ( $' \dot{\xi} \xi$ o $\nu \tau o s)$ in the sense that it comes to be from something existent, namely the unshaped block of marble that existed before. ${ }^{32}$ Every instance of generation is an instance of coming to be 'from being' in this sense: the new thing always comes to be from a previously existing precursor (see $\mathrm{I} .7, \mathrm{I}_{90} \mathrm{~b}_{\mathrm{I}} \mathrm{I}-\mathrm{I}$ ). So (i) holds in every case of coming to be.

Further, although it is true that the statue comes to be from being (in the above sense), it is not by virtue of its having previously been a being that the statue was able to come to be. After all, there are many beings from which statues are unable to come to be. Think of unsculptable stuffs such as fire or air, or of mathematical entities such as numbers and points. The explanation of why the statue was able to come to be is (once again) that the thing that currently has the statue form was previously an unshaped block of marble: an entity capable of possessing the statue form, but actually lacking it. So we can see that (ii) is true as well.

If a thing comes to be 'from being' in this way, we avoid the problem raised in the puzzle ('what is does not come to be, since it already is', I9 $\mathrm{I}^{\mathrm{a}} 30$ ). This is because the unshaped block of marble, though existent, is not already in the end state of the process whereby the statue comes to be. The end state of this process (the state into which the subject of the process changes) is not being or existence, but instead having the form of the statue. Thus, while it may be true that what already exists cannot now come into a state of existence, this does not mean that it cannot come into the end state of a process of generation.

I take Aristotle to be making this point about the end state of ${ }^{32}$ Of course, the statue does not come to be from its being existent. 
generation with claim (B): 'What is does not come to be, except accidentally'. This claim might be read in either of two ways. It might be saying $(\mathrm{BI})$ that what is does not enter into a process of coming to be, except accidentally. (On this reading claims (A) and (B) are simply terminological variants of one another.) Or it might be saying (B2) that what is does not result from a process of coming to be, except accidentally. The second reading is supported by Aristotle's subsequent argument for (B). He proceeds to argue that nothing comes to be a being non-accidentally $\left(\mathrm{I}_{9} \mathrm{I}^{\mathrm{b}} 24-6\right)$. This corresponds to $\left(\mathrm{B}_{2}\right)$ rather than to $\left(\mathrm{B}_{1}\right)$. It is a point about the end state of the process of coming to be, rather than a point about its origin state. ${ }^{33}$

Aristotle makes the point by way of a thought experiment: imagine that a horse transmutes into a dog. In this hypothetical scenario, the horse comes to be an animal only accidentally. While it is true that the horse has become a dog, and that the dog is an animal, it is not the case that being an animal is the end state of the change undergone by the horse. The horse was an animal already, and so could not have entered into a change the end state of which is being an animal. ${ }^{34}$

We should say the same thing about coming to be a being. When the block of marble is sculpted into a statue, the marble comes to be a being only accidentally. While it is true that the marble has become a statue, and that the statue is a being, it is not the case that being (or being a being) is the end state of the change undergone by the marble. The marble was a being already, and so it could not have entered into a change the end state of which is being. On Aristotle's view the same holds in every other instance of generation: in every case the subject of the process is a being already, and therefore being cannot be the end state of the process. The end state is instead the possession of the relevant form.

33 For the distinction between readings (BI) and (B2) see Kelsey, 'I 8', 350-7. Kelsey himself favours $\left(\mathrm{B}_{\mathrm{I}}\right)$, primarily because of the way the present section begins ('And in the same way ...'). This suggests that the point at $19 \mathrm{I}^{\mathrm{b}}{ }_{17-1} 8$ is meant to be parallel to Aristotle's previous point about coming to be from non-being. Since that was a point only about the origin state of coming to be (and not about its end state), Kelsey takes 'in the same way ...' to imply that at $\mathrm{I}_{9 \mathrm{I}}{ }^{\mathrm{b}}{ }_{\mathrm{I}} 7-\mathrm{I} 8$ Aristotle is once again making a point only about the process's origin state. I acknowledge that this is a consideration in favour of $(\mathrm{BI})$, but $\mathrm{I}$ think that it is outweighed by the fact that Aristotle's subsequent argument is most plausibly read as concerning the end state.

34 A good real-life analogy is Kelsey's case of a carpenter making a chair from an old table ('I 8', 336). The new chair is a piece of furniture, but being a piece of furniture is not the end state of the change undergone by the table. 
4.I.3. This does not violate the law of excluded middle The last remark Aristotle makes about the present way of addressing the puzzle is that it does not require us to posit a middle state between being and non-being:

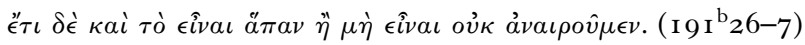

And further, we do not destroy [the principle that] everything either is or is not.

Everything either is or is not; the way to defuse the Eleatic puzzle is not to deny this, but to identify unproblematic ways in which a thing comes to be both from non-being and from being.

\subsection{The second way of addressing the puzzle}

A second way of addressing the puzzle is briefly mentioned at I 9 I $^{\mathrm{b}} 27-9$ :

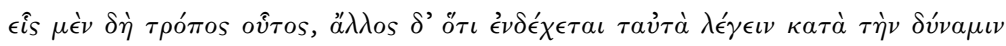

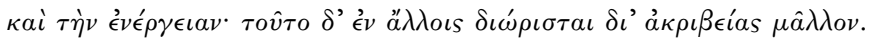

So this is one way [of addressing the puzzle]; another is that it is possible to speak of the same things in terms of potentiality and actuality. But this has been determined more precisely elsewhere.

The idea here would seem to be that there are two ways in which a thing can exist: either actually or potentially. When the matter of the statue (the marble) has the privation, the statue exists potentially. Once the matter has taken on the form, the statue exists actually. Generation can thus be thought of as a process in which a thing goes from existing potentially (when the matter has the privation) to existing actually (when the matter has the form). This means that there is another way in which, on Aristotle's theory of principles, a thing comes to be both from being and from non-being: it comes to be from a state of potential existence and from a state of actual non-existence.

As before, this avoids the Eleatic difficulties. We avoid the difficulty raised for the possibility of coming to be from being ('what is does not come to be, since it already is'), because the end state of the process of generation is not-on this view-the generated thing's existence, but rather its actual existence. Since the generated thing exists only potentially—not actually—at the beginning of the process, it is not already in the end state of the process. 
Again, the generated thing can come to be from being actually non-existent without this violating the principle that, in any change, 'something must underlie'. Although the generated thing does not exist actually prior to the process of generation, it does exist potentially. And a potentially existing thing-unlike something that exists neither actually nor potentially-can be the subject of a change. This is because a potentially existing $F$ is always numerically identical to an actually existing $G$. The potentially existing house, for instance, is numerically identical to an actually existing pile of bricks. It follows that the potentially existing house is capable of being affected, and is therefore capable of undergoing a change from one state to another.

\subsection{The source of the Eleatics' confusion}

Aristotle now concludes his discussion by pinpointing the ultimate source of the Eleatics' 'ignorance' about the possibility of coming to be:

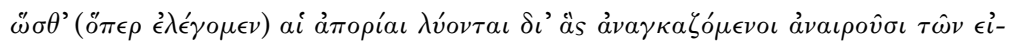

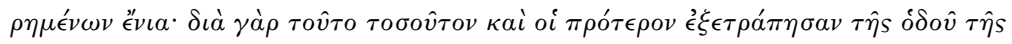

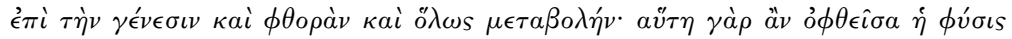

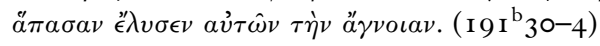

So, as we were saying, the puzzles on account of which they were forced to abolish some of the aforementioned things are resolved. For it was because of this that the earlier philosophers were also turned so far off course from the road leading to coming to be, passing away, and change in general. For this nature, had they seen it, would have dissolved all of their ignorance.

I want to focus on the last sentence. As becomes clearer from chapter 9, the phrase 'this nature' ( $a \tilde{\tau} \tau \eta \dot{\eta} \phi \dot{v} \sigma \iota s$ ) refers to what Aristotle had earlier (towards the end of chapter 7) called 'the underlying nature' ( $\dot{\eta} \dot{v} \pi \circ \kappa \epsilon \iota \mu \epsilon^{\prime} \eta \phi \dot{v} \sigma \iota s, \mathrm{I}_{9} \mathrm{I}^{\mathrm{a}}{ }^{7}-8$ ). That is, it refers to the substratum or the matter that, on Aristotle's theory, underlies the process of coming to be. ${ }^{35}$

I suggest that Aristotle thinks the Eleatics fail to 'see' the underlying nature in the sense that they fail to see what it is that underlies

35 So e.g. Ross, Physics, 497, and Charlton, Physics I-II, 8I. This reading of the phrase is confirmed by what happens in I. 9, where Aristotle discusses certain other philosophers-Plato and his followers-who had 'touched on it [sc. this nature], but not sufficiently' (I9 $\mathrm{I}^{\mathrm{b}} 35^{-6}$ ). Aristotle goes on to explain that these other philosophers had some notion of the underlying nature, but failed properly to distinguish the matter and the privation. 
in a process of coming to be. They conceive of coming to be as a change whose subject is not the matter but the thing that comes to be. It is this conception of coming to be that gives rise to the Eleatic puzzle. If a thing is to come into being, it cannot already exist. And yet something non-existent could not be the subject of any process at all. If we assume that the subject of the process of coming to be is the thing that comes to be, it apparently follows that coming to be is impossible.

Aristotle says that if these philosophers had seen the underlying nature, it would have 'dissolved all of their ignorance'. He means, I think, that the key to resolving the Eleatic puzzle is seeing what it is that underlies. And this is surely true. Once we recognize that the thing that underlies the process of coming to be is the matter, the puzzle disappears. ${ }^{36} \mathrm{We}$ may grant (i) that, prior to its coming to be, a thing does not exist, and (ii) that a non-existent thing cannot be the subject of a process or a change. But absent the assumption that the subject of coming to be is the thing that comes to be, these two claims exert no pressure on us to conclude that coming to be is impossible.

It should be noted that on Aristotle's theory we are still able to say that coming to be is a process in which a thing goes from not existing to existing. This is because of hylomorphism-the doctrine that whatever comes to be is a composite of matter and form. When the matter has the privation, the thing does not yet exist (in the sense that it does not yet exist actually); once the matter has taken on the form, the thing now exists (in the sense that it now exists actually). So although Aristotle's theory reconceives coming to be as a process undergone by the matter, it still preserves the commonsensical view that, when a thing comes to be, that thing goes from not existing to existing. ${ }^{37}$

\section{Conclusion}

Earlier in the paper I argued for an 'existential' interpretation of the Eleatic puzzle described at Phys. I. 8, I9I ${ }^{\mathrm{a}} 23-3$ I. I pointed

$3^{6}$ Cf. J. Barnes, Aristotle: A Very Short Introduction (Oxford, 2000), 79.

37 I therefore think that hylomorphism is an important part of Aristotle's answer to the puzzle about coming to be. For a contrary view, see S. Kelsey, 'Hylomorphism in Aristotle's Physics', Ancient Philosophy, 30 (2010), 107-24 at I I 5-I6. 
to several advantages of this interpretation: it avoids having the puzzle presuppose an Aristotelian distinction between substances and non-substances; it takes the passage's distinction between coming to be 'from what is' and 'from what is not' at face value; and it makes good sense of the subarguments given against each option. We have now seen a further merit of the interpretation: when the puzzle is understood in this way, Aristotle's theory of principles successfully resolves it, just as he claims. The puzzle, thus interpreted, depends on the assumption that the subject of coming to be is the thing that comes to be. The key Aristotelian move is to reconceive coming to be as a process whose subject is the matter, which changes from having the relevant privation to having the relevant form. With this alternative conception of coming to be the puzzle is resolved. As Aristotle shows in the second half of chapter 8, his theory allows him to identify ways in which a thing comes to be both from being and from non-being, and which avoid the Eleatic difficulties.

To say that Aristotle's theory successfully resolves the puzzle described in Physics I. 8 is not to say that he here provides a complete vindication of the possibility of coming to be. His theory raises further questions. For instance, on this view generation is a process in which a persisting substratum changes from having one property to having another. ${ }^{3}$ How, one might wonder, does this constitute the emergence of a new thing, rather than merely being the modification of what was already there? In what way does this process differ from a case of ordinary change, as when a person goes from being tanned to being pale? This is a genuine problem about generation, and one that Aristotle recognizes he needs to address. ${ }^{39}$ But it is distinct from 'the puzzle of the ancients' that is under consideration in Physics I. 8. If the puzzle of I. 8 is interpreted in the way I have suggested, it seems to me that Aristotle's response to it is a clear success.

\section{University of California, Berkeley}

${ }^{3} 8$ For a defence of the claim that, in the theory of Physics I, the matter persists through the process of generation, see A. Code, 'The Persistence of Aristotelian Matter', Philosophical Studies, 29 (1976), 357-67.

${ }^{39} \mathrm{He}$ addresses it in $G C_{\mathbf{I}}$. 


\section{B I B L I O G R A PHY}

Anagnostopoulos, A., 'Aristotle's Parmenidean Dilemma' ['Dilemma'], Archiv für Geschichte der Philosophie, 95 (2013), 245-74.

Angioni, L., Aristóteles: Física I-II (Campinas, 2009).

Barnes, J., Aristotle: A Very Short Introduction (Oxford, 2000).

Barnes, J., The Presocratic Philosophers, rev. edn. (London, I982).

Charlton, W., Aristotle: Physics, Books I and II [Physics I-II] (Oxford, 1970).

Code, A., 'Aristotle's Response to Quine's Objections to Modal Logic' ['Response'], Fournal of Philosophical Logic, 5 ( 1 976), I 59-86.

Code, A., 'The Persistence of Aristotelian Matter', Philosophical Studies, 29 ( 1976), 357-67.

Cornford, F. M., Plato and Parmenides (London, I939).

Horstschäfer, T. M., 'Über Prinzipien': Eine Untersuchung zur methodischen und inhaltlichen Geschlossenheit des ersten Buches der Physik des Aristoteles (Berlin, I 998).

Kelsey, S., 'Aristotle Physics I 8' ['I 8'], Phronesis, 5 I (2006), 330-6 I .

Kelsey, S., 'Hylomorphism in Aristotle's Physics', Ancient Philosophy, 30 (2010), 107-24.

Laas, E., Aristotelische Textes-Studien (Berlin, I863).

Loux, M. J., 'Aristotle and Parmenides: An Interpretation of Physics A 8', Proceedings of the Boston Area Colloquium in Ancient Philosophy, 8 ( I 992), 28I-3I9.

Madigan, A., 'Commentary on Loux', Proceedings of the Boston Area Colloquium in Ancient Philosophy, 8 (1992), 320-7.

Palmer, J., Parmenides and Presocratic Philosophy (Oxford, 2009).

Ross, W. D., Aristotle's Physics: A Revised Text with Introduction and Commentary [Physics] (Oxford, I936).

Wagner, H., Aristoteles: Physikvorlesung (Berlin, I967).

Waterlow, S., Nature, Change, and Agency in Aristotle's Physics: A Philosophical Study (Oxford, I 982).

Wicksteed, P. H., and Cornford, F. M., Aristotle: The Physics, Books IIV (Cambridge, Mass., I 934). 